\title{
Prestress Accumulation-Release Technique for Damping of Impact-Born Vibrations: Application to Self-Deployable Structures
}

\author{
Arkadiusz Mróz, ${ }^{1}$ Jan Holnicki-Szulc, ${ }^{1}$ and Jan Biczyk ${ }^{2}$ \\ ${ }^{1}$ Intelligent Technology Department, Institute of Fundamental Technological Research, Polish Academy of Sciences, \\ Ulica Pawińskiego 5B, 02-106 Warszawa, Poland \\ ${ }^{2}$ Adaptronica Sp. z o. o., Ulica Szpitalna 32, 05-092 Łomianki, Poland
}

Correspondence should be addressed to Arkadiusz Mróz; amroz@ippt.pan.pl

Received 27 October 2014; Accepted 6 February 2015

Academic Editor: Sivaguru Ravindran

Copyright @ 2015 Arkadiusz Mróz et al. This is an open access article distributed under the Creative Commons Attribution License, which permits unrestricted use, distribution, and reproduction in any medium, provided the original work is properly cited.

\begin{abstract}
A numerical study is presented, which tailors so-called prestress accumulation-release (PAR) strategy to mitigate free vibrations of frame structures. First, the concept of proposed semiactive technique is outlined and possible applications are specified. In the second part of the work a parametric study is discussed, which illustrates the potential of the method for mitigation of free vibrations induced by impact or other initial load scenarios. Special attention is given to the energy balance including all relevant contributions to the total energy of the considered dissipative system. The proposed technique shows a very high potential in mitigation of free vibrations, exceeding $99 \%$ of the reference amplitude after 5 cycles of vibration.
\end{abstract}

\section{Introduction}

1.1. Problem Outline. Some engineering structures are exposed to transient dynamic loading which, although not dangerous for the structure itself, may generate harmful or undesirable effects. It has been therefore an engineering problem to eliminate vibrations induced by nondestructive impacts, force impulses generated by working machinery, and so forth. Effective mitigation of such vibration might, for example, help improve the resolution of optical equipment or reduce the noise generated by vibrating structure. Out of three classes of possible solutions, that is, passive, active, and semiactive, there has been growing attention to the semiactive methods which allow for adjusting some mechanical parameter characteristic on one hand and utilise the structural deformation to introduce control forces, on the other hand. One advantage of the latter feature, which is common with passive devices, is that the system does not require external power to directly generate the control forces. The external power is needed to regulate an actuator which in turn changes the magnitude of the control force according to the control unit algorithm and is typically in the order of magnitude of tens of Watts. Symans and Constantinou in [1] give definitions of all three classes of methods and provide a review of semiactive solutions for seismic protection of structures. In particular a reference is given to a stiffness control device introduced by Kobori et al. [2], where bracing of a frame structure is locked or unlocked in order to keep the structural response at lowest possible level during an earthquake. Also, the design assures that in the power failure situation the structure works with maximum stiffness, that is, with the bracing locked.

Another group of techniques which gained attention especially in seismic engineering is utilisation of semiactive friction dampers for energy dissipation. Such dampers can be installed either within a structure as part of additional bracing $[3,4]$, or as adaptive stiffeners between adjacent structures [5, 6 ]. In either case the slip condition and the friction generating contact force can be controlled with a piezoelectric actuator. A similar approach has been adopted in the present study.

Among many available concepts of tailoring semiactive techniques to mitigate vibration, synchronised switch damping (SSD) techniques generate voltage magnification, and a phase shift between the mechanical strain and the resulting 
voltage of a piezoelectric element. As a result a force always opposite to the velocity is obtained and the level of dissipation corresponds to the part of mechanical energy converted into electric energy. A review of SSD and other semiactive techniques utilising piezoelectric elements is given in [7]. Another interesting example of coupling structural response with PZT actuators is given in work [8].

Technical application of adaptive shock-absorbers to adaptive landing gears and vehicle suspension is discussed, respectively, in $[9,10]$. Other semiactive technical solutions for mitigation of impact loads are presented in [11-13]. The concept described in [14] deals with the use of on-off rod connections control for energy dissipation in a flexible truss-beam structure, whereas in [15] a concept is proposed for vibrations suppression in a mass-spring system due to a controlled detaching and reattaching of a spring. In the present work another semiactive technique is analysed which aims at mitigation of free vibrations. Its efficiency is demonstrated numerically on an example of frame, selfdeployable structure.

\subsection{Prestress Accumulation-Release (PAR) Strategy as a Semi-} active Technique. In the PAR strategy it is assumed that a structure undergoes free vibrations and that there is a certain device or devices installed in the structure capable of imposing kinematic constraints on some degrees of freedom of the system. For instance, a layered beam could be equipped with a device that allows or constrains the relative slip between layers, or a system composed of masses, and springs is equipped with a device which releases or reattaches a chosen spring to a mass. Given such devices are in place, the strain accumulated in the structure could locally be released which results in conversion of a part of the strain energy to the kinetic energy of local, higher frequency vibrations. In the next phase constraints are reimposed which results in "freezing" of a part of the deformation. Local, higher frequency vibrations introduced after reimposing of the constraints can be effectively damped out with material damping. An interesting, example of a passive TMD device for damping portions of kinetic energy locally in order to achieve global mitigation effect is described in [16].

If the time instant of reimposing constraints is chosen properly, that is, at the moment of maximum relative dislocation between top and bottom beam, it will introduce a prestress in the structure. It should be emphasised at this point that a relatively small energy was used to adjust the actuator device, for example, a piezo actuator that controls the friction in a joint (like one introduced by Gaul and Nitsche [17]) and in turn a control force was generated in the structure that is a result of the structural motion itself. Furthermore the generated prestress acts in the direction that opposes the movement of the structure. As mentioned in [1] such a behaviour is desirable for many semiactive techniques because it promotes the stability of the system. Obtained prestressed structure, with a new equilibrium configuration, could then return to the initial state by means of a gradual, quasi-static release of the prestress accompanied by the frictional dissipation in the contact surfaces. For many practical cases the above procedure needs to be repeated until the desired effect is obtained. As a result a very high potential in the mitigation of the fundamental mode of vibrations is achieved.

\section{Numerical Model}

2.1. Introduction. Some numerical as well as experimental results of application of the PAR technique to layered beams can by found in [18], where on-off control was applied to adjust relative movement of adjacent structural layers. In the present study a frictional joint is assumed in the nodes of a frame structure allowing for continuous adjustment of the moment bearing capability of semiactive nodes. For demonstrative purposes the assumed frame ends with a hinge with a panel attached to it (cf. Figure 1). In the simulations the panel opens according to a prescribed angular velocity profile. Panel opening is initiated with a micro blast located at the end of the main structure. Both the micro blast force and step changes in the panel opening angular velocity are the sources for the free vibrations of the structure which are then subject for mitigation with PAR technique.

\subsection{Assumed Model of a Frame Cantilever with Semiactive} Nodes. Physical model analysed in numerical simulations was a one meter long cantilever beam comprising two layers $0.1 \mathrm{~m}$ apart and connecting elements spaced every $0.1 \mathrm{~m}$. Two frictional joints at both ends of each connecting element (depicted in green in Figure 1) governed the rotation in the node about the $X_{3}$ axis. Semiactive frictional joints allowed for continuous, controlled adjustment of the normal force between the frictional surfaces, thus allowing for adjusting friction between the adjacent surfaces. This, in turn, allowed for the smooth transition between frame nodes and truss nodes. Frame mode of a semiactive node corresponds to a maximum normal force applied to the frictional surfaces and consequently no slip between these surfaces within the design range of bending moments, whereas the truss mode corresponds to minimum normal force and consequently negligible moment bearing capability in the nodes.

All cantilever members were modelled as steel, prismatic, and rectangular bars with cross-section of $20 \times 6 \mathrm{~mm}$.

There are two physical sources of energy dissipation in the assumed model:

(1) material damping,

(2) friction between surfaces of semi-active nodes.

Ad. (1) Rayleigh damping model was assumed, taking the form $[C]=\alpha[M]+\beta[K]$, with mass and stiffness coefficients, respectively $\alpha=1.0 e-6$ and $\beta=1.0 e-5$.

Ad. (2) Coulomb friction model in accordance with [19] was utilised with the slip condition: $\Phi=$ $\left|M_{t}\right|-\mu M_{n} \leq 0$, where $M_{n}$ is the generalized force produced due to the contact, $M_{t}$ stands for tangential traction carried by the contacting surfaces and $\mu M_{n}$ is the maximum shear before slip occurs. The coefficient of friction $\mu=0.1$ 


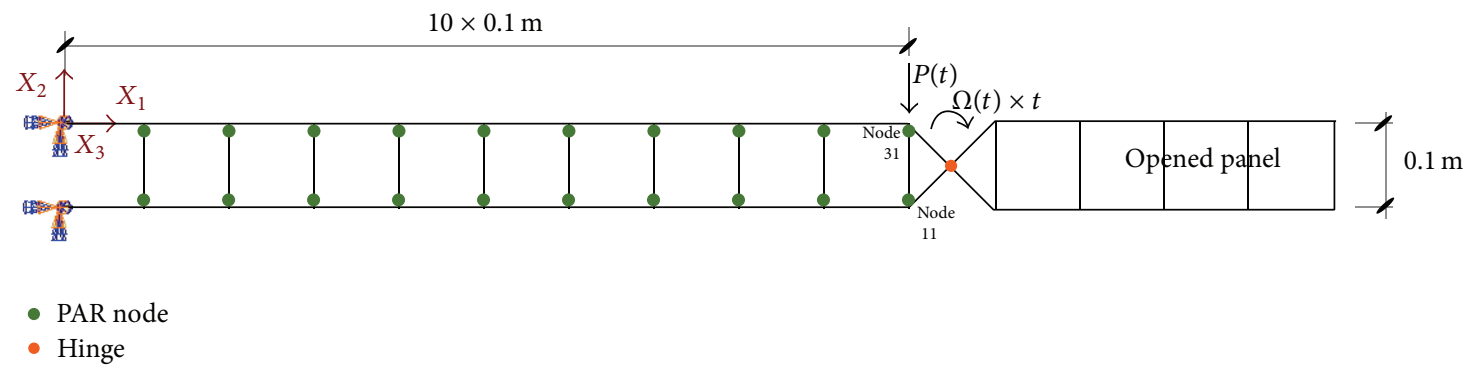

FIGURE 1: Structure assumed in the simulations (semiactive nodes depicted in green).

was assumed in the simulations. The value of $M_{n}$ was adjusted according to the algorithm defined in a user subroutine and outlined in Figure 2.

2.3. Proposed Control Strategy. In the outline of the control strategy presented in Figure 2 the control procedure begins with the structure working in the frame mode; that is, there is maximum friction generating moment $M_{n}$ applied in the nodes. If the maximum deflection of the oscillatory movement at the cantilever tip is detected then the applied moment drops to zero and thus the transition of the nodes to the truss mode occurs. It results in the longitudinal dislocation of the two main layers in direction $X_{1}$. Now, control algorithm awaits for the detection of the maximum displacement of layers in $X_{1}$ direction in order to increase the $M_{n}$ to maximum again. If the simulation was terminated at this point, the structure would come to a new equilibrium position, which differs from the original one. It is however desired for the structure to come back to the original state. Therefore the $M_{n}$ is gradually decreased, allowing for limited slip between the contact surfaces, which in turn results in quasistatic return of the structure to the original configuration. In this phase the value of $M_{n}$ is decreased by few percent if there is no slip between contact surfaces or is kept without change, otherwise. Finally, the maximum value for the $M_{n}$ is restored, provided that the structure is sufficiently close to the initial configuration. This condition can be monitored, for example, with relative displacement of tips of top and bottom beam in $X_{1}$ direction.

The control strategy could be summarised as follows.

Phase 1. Upon detection of maximum displacement amplitude trigger the sequence of semiactive nodes transition from frame to truss and, after a very short period of time, back to frame mode.

Phase 2. Gradually release the friction generating moment and monitor the structure return to the initial configuration.

Phase 3. Restore the full stiffness and go back to Phase 1, if needed.

\section{Results of Simulations}

3.1. Introduction. Numerical simulations were carried out with Abaqus/Standard Finite Element Software using finite

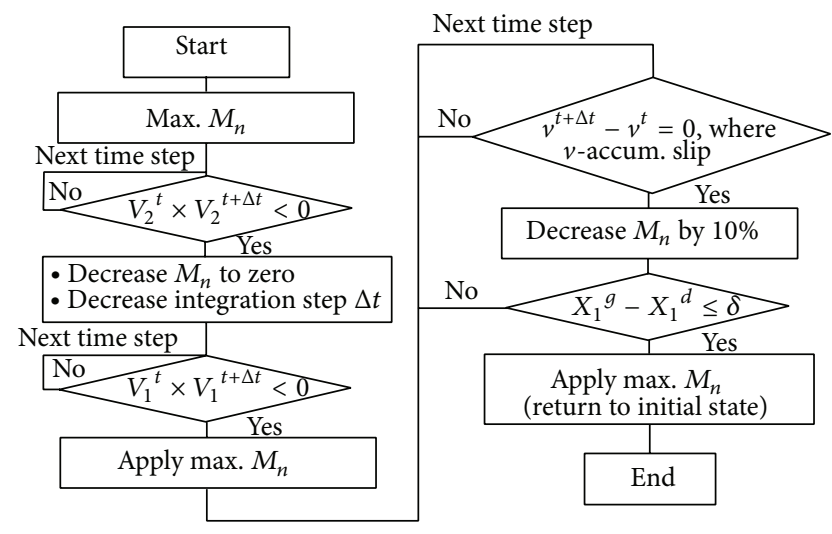

Figure 2: Control strategy outline.

displacement theory because of large rotations during opening of the panel. Semiactive nodes were modelled with connector elements in which the available component of relative motion was the rotation about $X_{3}$ axis with frictional behaviour defined. Nonlinear behaviour of the semiactive nodes was introduced as the friction generating force was a nonlinear function of a control variable updated in a feedback loop via a Fortran user subroutine.

The fundamental mode of vibration of the assumed model with the opened panel was

(i) $19.6 \mathrm{~Hz}$ for structure with frame nodes,

(ii) $3.96 \mathrm{~Hz}$ for structure with truss nodes.

The first longitudinal eigenfrequency was 1213.4 and $1186.8 \mathrm{~Hz}$, respectively.

3.2. Response of the System with All Nodes Semiactive. In the initial simulation all semiactive nodes (indicated by green spots in Figure 1) were activated. The vertical displacement of the cantilever tip is depicted in Figure 3. As can be seen switching semiactive nodes from frame mode to truss and back qualitatively changes the behaviour of the vibrating structure. The prestress is then gradually unloaded which results in slow return to the base state. The same process is shown in Figure 5 in terms of the accumulated slip between the frictional surfaces. A step change in the slip is triggered with the friction generating moment reduced to zero for 


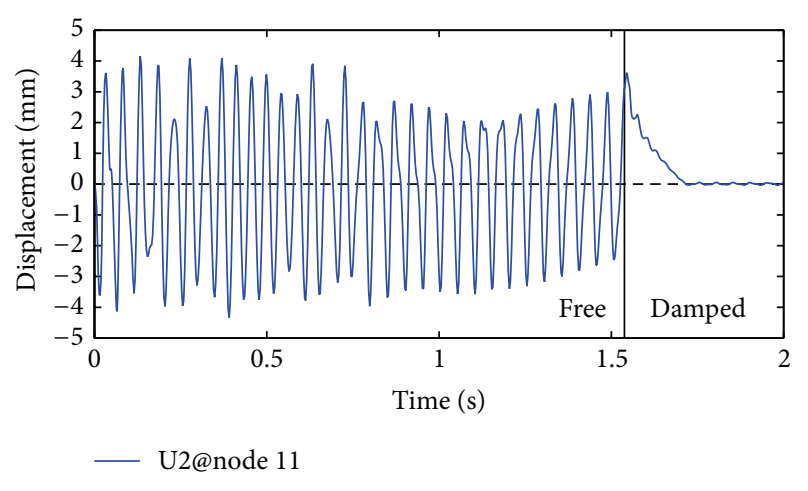

FIgURE 3: Vertical displacement at the tip of main structure (node 11).

a very short period of time. The remaining slip is accumulated during gradual decrease of the friction generating moment. During this phase semiactive nodes are in the transition state between frame and truss. Sufficient unloading of the prestress triggers the return of semiactive nodes to the frame mode. Then the whole procedure may be repeated if needed. In the shown example $90.4 \%$ of the vibration amplitude was mitigated after time period corresponding to 5 cycles of vibration. Accordingly, after 13 cycles of vibration $99.6 \%$ of the amplitude was mitigated.

The longitudinal displacements of the top and bottom layer's tip are shown in Figure 4. Switching to truss mode and back introduces higher frequency vibrations which correspond to the identified longitudinal eigenmode. These vibrations are effectively damped out with material damping.

For this particular case the nodes are switched at the point of maximum $+X_{2}$ displacement. Switching to truss mode results in top beam tip (node 31) travelling in $+X_{1}$ direction, whereas bottom beam tip (node 11) travelling in $-X_{1}$ direction (cf. Figure 4(b)) which, after switching back to frame mode, introduces a prestress in both beams (cf. Figure 6). Vertical lines in Figure 4(b) refer to switching from frame to truss mode and back from truss to frame, respectively.

3.3. Energy Balance. The sum of mechanical energy of the system, energy dissipated and the work of external forces done on the structure must remain constant throughout the process. For the analysed system undergoing free vibrations there are following nonzero components of the total energy balance:

(i) kinetic energy,

(ii) strain energy,

(iii) energy dissipated in viscous processes, including material damping,

(iv) frictional dissipation at contact surfaces of semiactive nodes.

All of the above contributions are depicted in Figure 7. It can be observed that the primary source for energy dissipation is the material damping of higher frequency vibrations introduced with the activation of nodes. Frictional dissipation also contributes to the system balance, however to a smaller extent. Energy dissipation contributions, begining at the time instant of nodes activation, amount to $84 \%$ for material damping and $16 \%$ for frictional dissipation. A slight decrease in the total energy balance can also be observed. This is because there is additional dissipation, not associated with any physical process but with the HilberHughes numerical integration scheme of the equations of motion. For the analysed example the amount of numerical damping introduced between the time instant just before the nodes activation and the end of simulation was $1.8 \%$.

\section{Parametric Study}

Based on the carried out initial simulations the following parameters have been identified to have an important impact on the system performance:

(1) material damping,

(2) number of semiactive nodes,

(3) amount of decrease in the friction generating moment in phase 2.

4.1. Material and Numerical Damping. First, the influence of numerical damping on the solution needs to be analysed. According to [19] in the implicit integration of equations of motion a slight numerical damping is introduced as an additional parameter in Hilber-Hughes-Taylor algorithm. For most cases the value of $\alpha_{\mathrm{HH}}=-0.05$ is a good choice. However, in order to verify that the efficiency of the proposed solution is not significantly affected with the numerical damping, values of $\alpha_{\mathrm{HH}}$ increased by $50 \%$ and $100 \%$ with respect to the default value were also analysed. Results shown in Figure 8 indicate that the increased value of numerical damping affects the time evolution of the solution; it does not however improve the overall efficiency. On the other hand too little numerical damping results in too much numerical noise in the solution which affects the control algorithm and thus also the global response. Decreasing $\alpha_{\mathrm{HH}}$ should therefore be avoided (cf. red curve in Figure 8).

As mentioned before, mass and stiffness proportional damping coefficients of the Rayleigh model are $\alpha=1.0 e-6$ and $\beta=1.0 e-5$, respectively. According to a well known formula for modal damping coefficient $\xi_{i}$ corresponding to $i$ th eigenmode,

$$
\xi_{i}=\frac{\alpha}{\omega_{i}}+2 \beta \omega_{i}
$$

damping of the 1st bending mode and the first antisymmetric longitudinal mode is equal to $\xi_{5}=0.2 \%$ and $\xi_{34}=15.2 \%$, respectively. Thus, assumed damping coefficients provide slight damping of the main oscillatory movement of the structure, while introducing substantial damping of the higher frequency vibrations generated after phase 1 . In another simulation a coefficient $\beta$, which has more impact on higher frequency damping, has been decreased by factor of 10 . This gives $\xi_{5}=0.02 \%$ and $\xi_{34}=1.52 \%$. Based on the results 


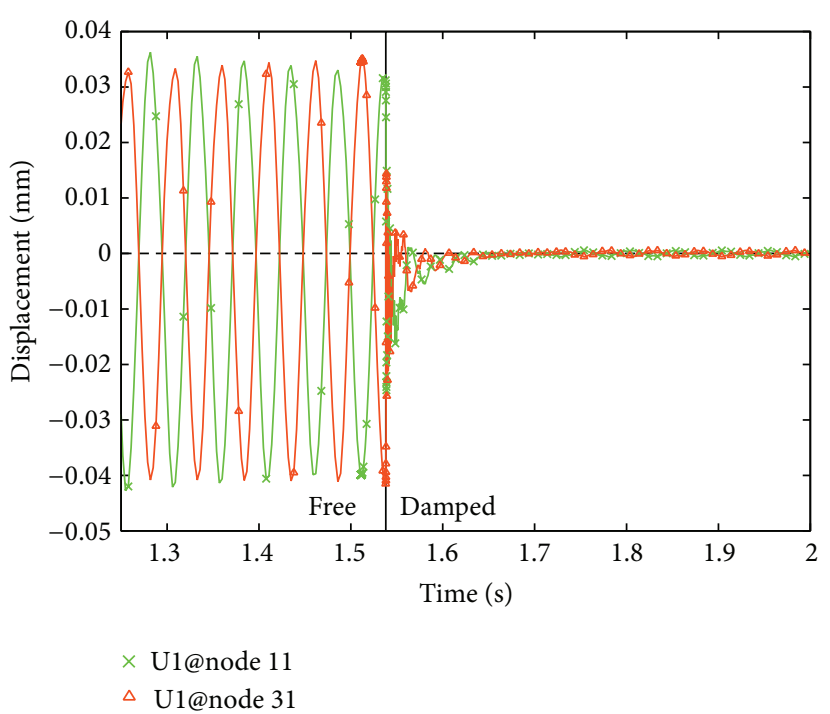

(a)

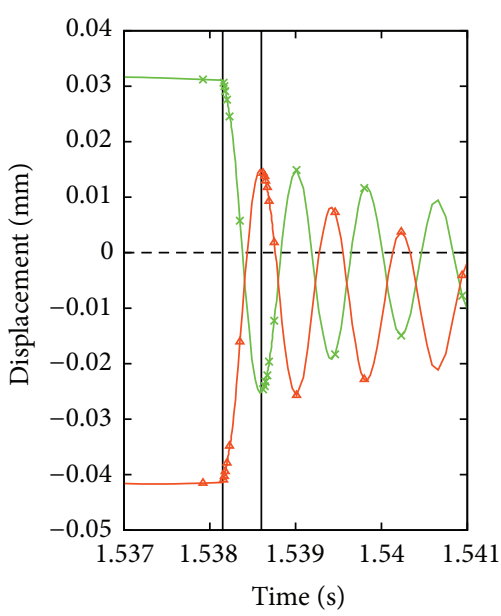

(b)

FIGURE 4: Horizontal displacement of tips of top (node 31) and bottom (node 11) layers: (a) full time history; (b) longitudinal vibrations triggered with nodes activation.

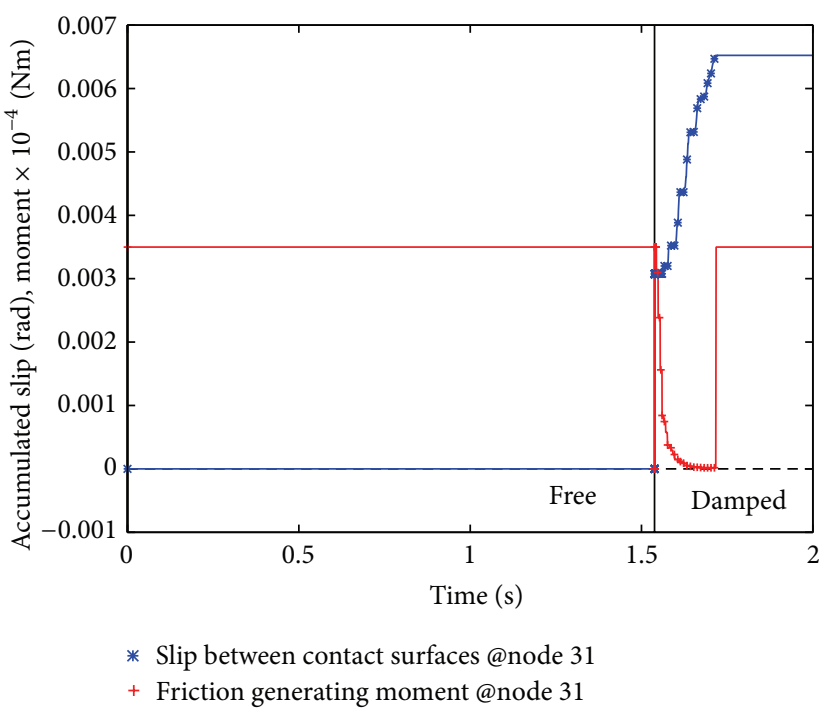

(a)

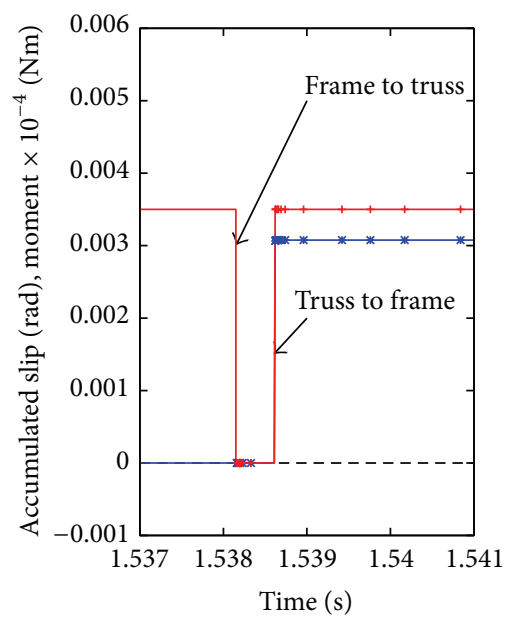

(b)

FiguRE 5: Accumulated slip between contact surfaces and the actuator moment: (a) full time history; (b) time window where zero moment corresponds to the truss mode.

shown in Figure 9(b) it can be concluded that if damping is decreased; it takes more time for the higher frequency vibrations to be ceased, but in both cases energy dissipated with material damping is similar (4.3\% difference in analysed cases). The overall mitigation of vertical displacement amplitude is also comparable (cf. Figure 9(a)) amounting to $96.5 \%$ after time period of 13 cycles of reference vibration.

4.2. Number of Semiactive Nodes. Preceding results have been obtained with all semiactive nodes connecting top and bottom beam. In this section the number of semiactive nodes is reduced. Namely, starting from the fixed support, only 1, 3, or 7 pairs of nodes were semiactive, while the remaining ones were kept as passive frame connections (cf. Figure 10(b)). In these cases not all the stress accumulated in top and bottom layers could be released with activation of nodes and thus less energy could be transferred to the longitudinal vibration of top and bottom layers. As a consequence the control algorithm needed to activate nodes transition more then once in order to obtain the desired effect (cf. Figure 10(a)). Nevertheless, in all considered cases, except the case with one pair of semiactive nodes, more than $90 \%$ of amplitude mitigation was obtained. Comparison of the vertical displacement 

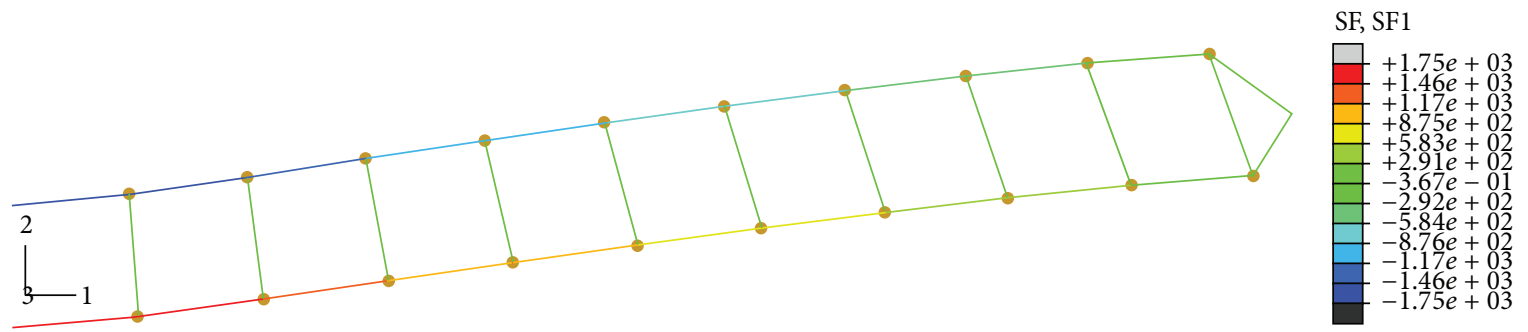

(a)
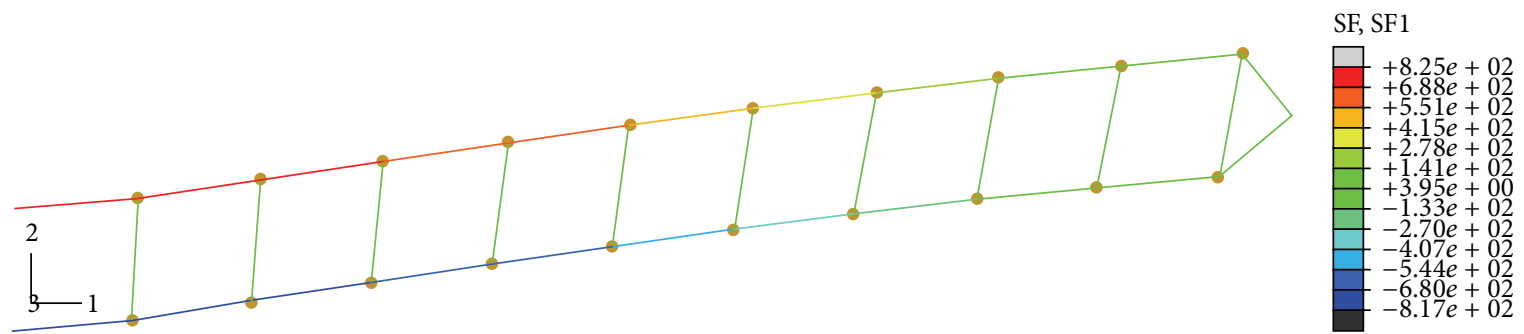

(b)

Figure 6: Axial force in beam elements (a) before and (b) after switching from frame to truss mode and back. Deformation scale U1x500, U2x40 (opened panel not shown).

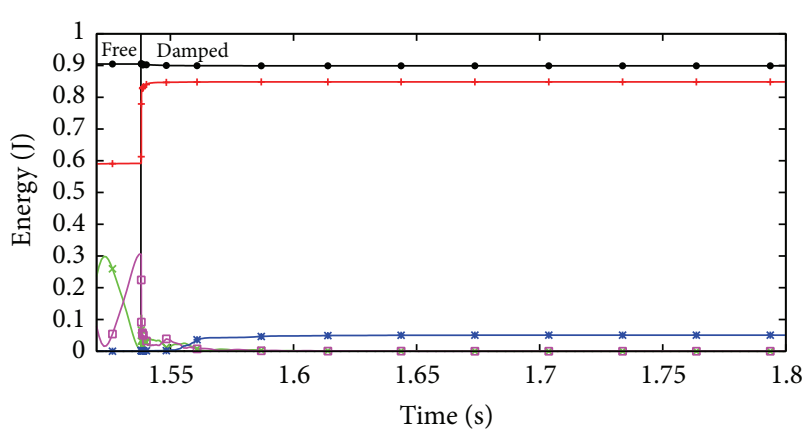

$\times$ Kinetic energy, KE

- Strain energy, SE

+ Viscous dissipation, VD

FIGURE 7: Energy balance of the whole system.

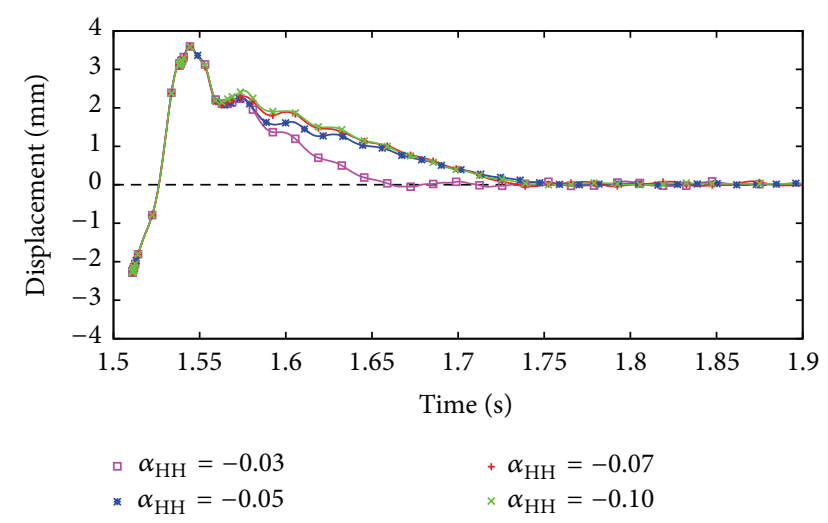

FIGURE 8: Influence of numerical damping on the solution.
TABLE 1: Vertical displacement amplitude mitigation with varying number of semiactive nodes.

\begin{tabular}{lcc}
\hline $\begin{array}{l}\text { Number of } \\
\text { semiactive nodes }\end{array}$ & $\begin{array}{c}\text { Vertical amplitude } \\
\text { reduction }\end{array}$ & $\begin{array}{c}\text { Number of node } \\
\text { activations }\end{array}$ \\
\hline 10 & $99.4 \%$ & 1 \\
7 & $98.3 \%$ & 2 \\
3 & $90.8 \%$ & 6 \\
1 & $56.7 \%$ & 9 \\
\hline
\end{tabular}

amplitude mitigation after 5 cycles of reference vibration is shown in Table 1.

4.3. Amount of Decrease in the Friction Generating Moment in Phase 2. As indicated in Figure 2 in the second phase of the process the prestress introduced into the structure is gradually unloaded by means of decreasing friction in semiactive nodes. This can be done slowly resulting in a quasistatic return of the system to the base state, or more rapidly. In the first case the final effect in terms of mitigated amplitude of vertical displacement is more pronounced, but it takes much more time; that is, the structure works with reduced stiffness for longer time. In the second case the mitigation is fast, but some left-over vibration is introduced when the full stiffness is restored (cf. Figure 11). In an additional case the maximum value of $M_{n}$ is preserved throughout the whole simulation which corresponds to oscillation about a new equilibrium position (cf. black line in Figure 11).

In Table 2 results are compared in terms of the efficiency of the vertical displacement mitigation after 5 and 13 cycles of reference vibration. Each row corresponds to a simulation with different value of $M_{n}$ decrease upon detecting a time increment without slip between contact surfaces. Note that 


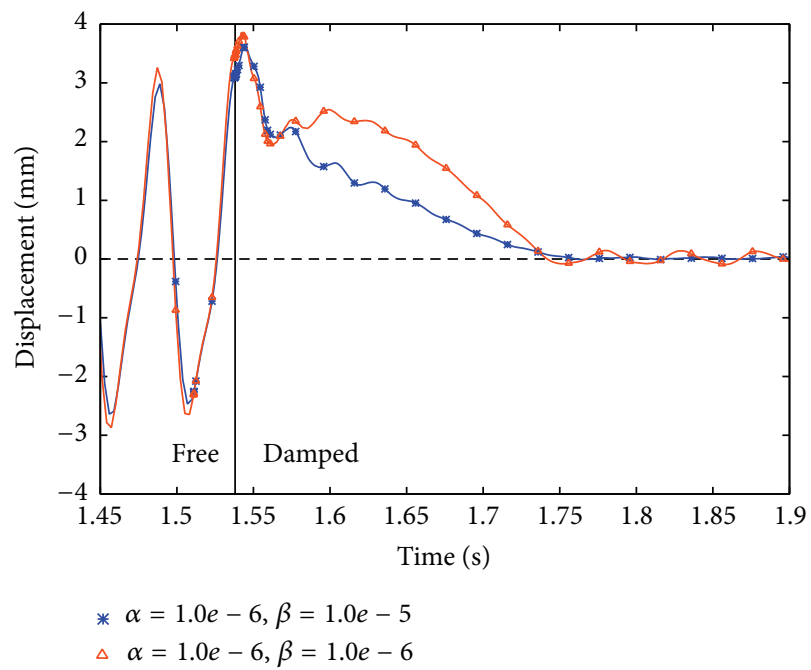

(a)

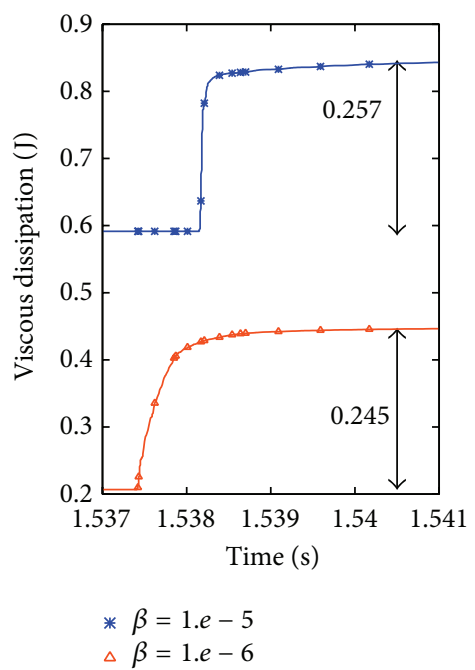

(b)

FIGURE 9: Influence of decrease of stiffness proportional damping: (a) in terms of vertical displacement of the bottom beam tip (node 11); (b) in terms of viscous dissipation during phase 1.

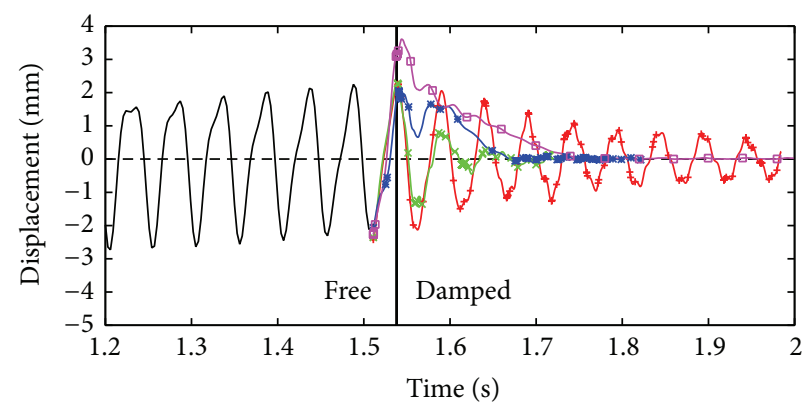

+1 pair of active nodes

$\times 3$ pairs of active nodes

(a)

* 7 pairs of active nodes

$\square 10$ pairs of active nodes

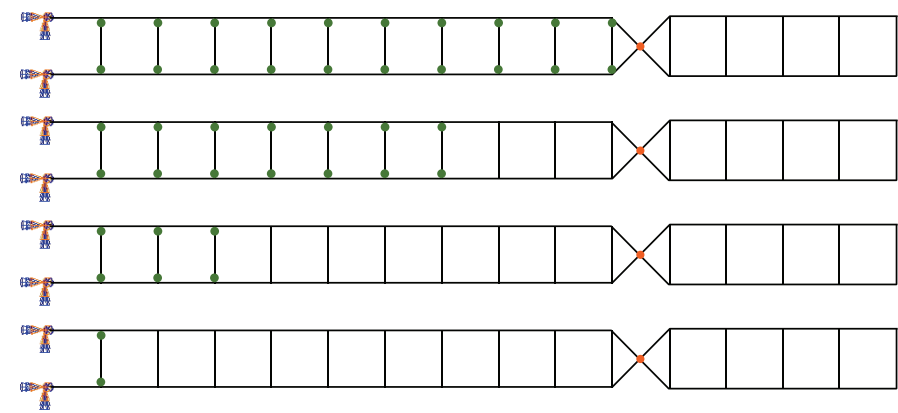

(b)

FIGURE 10: Varying number of semiactive nodes: (a) vertical displacement at node 11; (b) 10, 7, 3, and 1 pair of semiactive nodes location.

TABLE 2: Amplitude mitigation obtained with different values of friction generating moment decrease in Phase 2.

\begin{tabular}{lcc}
\hline \multirow{2}{*}{$\%$ of $M_{n}$ reduction } & \multicolumn{2}{c}{$\%$ of amplitude reduction after } \\
& 5 cycles of vibration & 13 cycles of vibration \\
\hline $5.0 \%$ & $61.9 \%$ & $71.6 \%$ \\
$6.0 \%$ & $73.2 \%$ & $81.3 \%$ \\
$7.5 \%$ & $96.2 \%$ & $99.4 \%$ \\
$10.0 \%$ & $99.1 \%$ & $99.2 \%$ \\
$11.5 \%$ & $98.5 \%$ & $98.3 \%$ \\
$20.0 \%$ & $96.3 \%$ & $96.4 \%$ \\
\hline
\end{tabular}

results presented in Figure 11 and in Table 2 refer to a single activation of nodes.

\section{Discussion}

In this paper a method for semiactive mitigation of free vibrations has been presented. In the so-called PAR strategy, the strain energy accumulated in the system during vibration is transferred to kinetic energy of higher frequency, longitudinal vibrations of the structural members, and eventually efficiently dissipated with material dissipation. In addition PAR strategy introduces an elastic control force into the structure which acts in direction opposing the movement. This prestress acts as a braking force to the vibration. Energy accumulated in prestress is gradually dissipated in the second phase of the control procedure with frictional joints of semiactive nodes. The efficiency of this approach has been demonstrated on a case study of a frame structure. Generally the efficiency is very high, although it depends strongly on the number of semiactive nodes installed in the structure. With few semiactive nodes installed it takes more activations of the nodes to obtain the desired effect, whereas if all nodes are semiactive only a single activation suffice. It has also been shown that the global response is dependent on the algorithm of applying the normal force in the frictional connections. Therefore, apart from the simple on-off strategy for applying the contact force in semiactive nodes, also other strategies are 


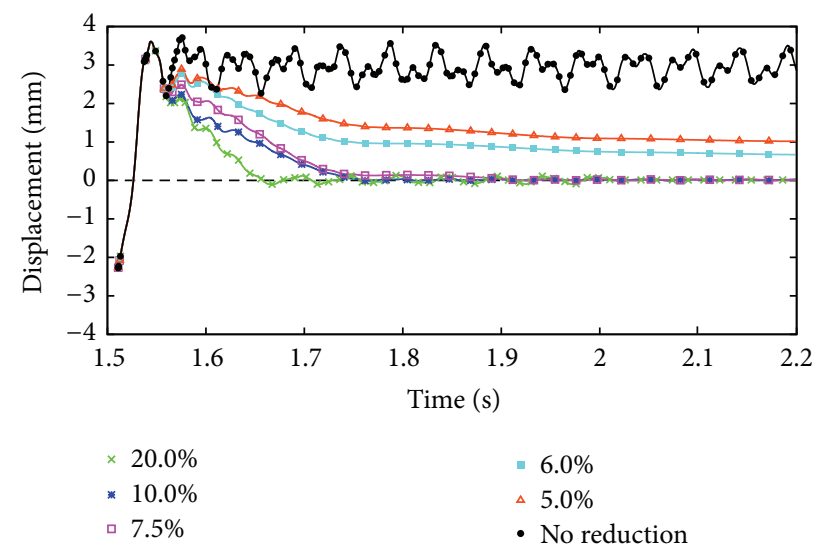

FIGURE 11: Vertical displacement at node 11 for different values of $M_{n}$ reduction.

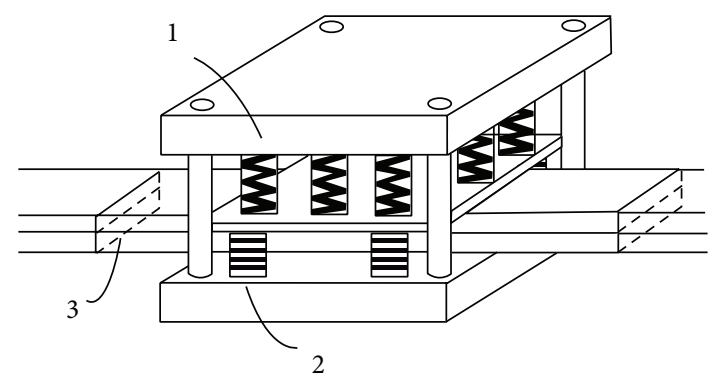

(1) Prestressed passive spring

(2) Idle actuator, no supply voltage

(3) Layers pressed together with prestressed springs

(a)

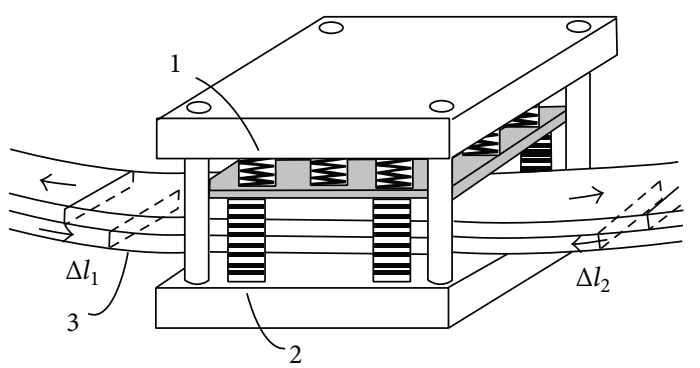

(1) Passive springs prestress neutralised with actuators

(2) Activated actuator, max. control voltage

(3) Structural layers mutually independent

(b)

FIGURE 12: Example of reliable PAR node: (a) full stiffness state, no supply voltage required; (b) reduced stiffness state, supply voltage required.

possible, based on the feedback with the slip between contact surfaces.

Generally the PAR strategy requires that the stiffness of the structure is temporarily reduced. Time duration of the minimum stiffness mode is however very short as compared with the time of full stiffness mode.

Carried out simulations indicate some difficulties one would encounter during development of the prototype system. It seems challenging to properly reimpose the full stiffness mode since the frequency of the longitudinal vibrations is relatively high, especially as the monitoring of the relative displacement between structural elements should be avoided for the sake of simplicity. This problem however could be overcome since the frequency of the longitudinal vibration is known a priori and could be used to set the time shift of switching between two modes of the semiactive nodes.

Another problem deals with the reliability of the structure. One possible realisation of semiactive nodes could be based on the concept presented in [17], where a semiactive frictional joint controlled with piezoelectric actuator is described. That solution, however, requires the supply voltage in order to operate in the stiff mode, which could cause problems in the situation of power failure. In a reliable semiactive node supply voltage should reduce the stiffness, as for example, in a patent description [20] applicable for layered beam. Under normal operating conditions contact force generated between layers by means of prestressed passive springs produces enough friction for the structural layers to work together (cf. Figure 12(a)), that is, with nominal bending stiffness. On the other hand, if the longitudinal vibrations need to be triggered, the prestress in passive springs is neutralised with the supply voltage applied to actuators. In this case the structural bending stiffness is reduced as both layers work independently (cf. Figure 12(b)).

Another example of a reliable semiactive system used in a seismic protection device is described in [2].

From general point of view the following problem can be formulated: "how to design optimally adaptive structure (equipped with controllable, semiactive PAR joints) able to reduce maximally vibrations caused by predefined impact" and this paper presents one of such desired solutions.

\section{Conflict of Interests}

The authors declare that there is no conflict of interests regarding the publication of this paper. 


\section{Acknowledgments}

Financial support of Structural Funds in the Operational Programme-Innovative Economy (IE OP) financed from the European Regional Development Fund, Project "Modern material technologies in aerospace industry," no. POIG.01.01 $.02-00-015 / 08-00$, is gratefully acknowledged. Financial support of Structural Funds in the Operational ProgrammeInnovative Economy (IE OP), Project "Innowacyjne technologie dla poprawy bezpieczestwa maego lotnictwa SWING (Safe-Wing)," no. POIG.01.04.00-14-100/09, POIG.04.01.00$14-100 / 09$, is gratefully acknowledged. Financial support of Polish research project, founded by NCN: "Podstawy adaptacyjnej absorpcji udaru (AIA: Adaptive Impact Aborption) oraz studium wykonalnoœci jej zastosowania do redukcji szkd w kolizjach transportowych," 2012/05/B/ST8/02971, is gratefully acknowledged.

\section{References}

[1] M. D. Symans and M. C. Constantinou, "Semi-active control systems for seismic protection of structures: a state-of-the-art review," Engineering Structures, vol. 21, no. 6, pp. 469-487, 1999.

[2] T. Kobori, M. Takahashi, T. Nasu, N. Niwa, and K. Ogasawara, "Seismic response controlled structure with active variable stiffness system," Earthquake Engineering \& Structural Dynamics, vol. 22, no. 11, pp. 925-941, 1993.

[3] Y. L. Xu and B. Chen, "Integrated vibration control and health monitoring of building structures using semi-active friction dampers. Part I-methodology," Engineering Structures, vol. 30, no. 7, pp. 1789-1801, 2008.

[4] B. Chen and Y. L. Xu, "Integrated vibration control and health monitoring of building structures using semi-active friction dampers: Part II—numerical investigation," Engineering Structures, vol. 30, no. 3, pp. 573-587, 2008.

[5] C. L. Ng and Y. L. Xu, "Semi-active control of a building complex with variable friction dampers," Engineering Structures, vol. 29, no. 6, pp. 1209-1225, 2007.

[6] A. V. Bhaskararao and R. S. Jangid, "Seismic analysis of structures connected with friction dampers," Engineering Structures, vol. 28 , no. 5, pp. 690-703, 2006.

[7] J. Qiu, H. Ji, and K. Zhu, "Semi-active vibration control using piezoelectric actuators in smart structures," Frontiers of Mechanical Engineering in China, vol. 4, no. 3, pp. 242-251, 2009.

[8] F. Dell'Isola and S. Vidoli, "Damping of bending waves in truss beams by electrical transmission lines with pzt actuators," Archive of Applied Mechanics, vol. 68, no. 9, pp. 626-636, 1998.

[9] G. Mikułowski and Ł. Jankowski, "Adaptive landing gear: optimum control strategy and potential for improvement," Shock and Vibration, vol. 16, no. 2, pp. 175-194, 2009.

[10] M. Makowski and L. Knap, "Reduction of wheel force variations with magnetorheological devices," Journal of Vibration and Control, vol. 20, no. 10, pp. 1552-1564, 2014.

[11] A. Mroz and J. Grzedzinski, "Method for securing mechanisms for wind turbine against the effects of sudden, excessive burdens and a system for securing the blades of the wind turbine," pl398448, Urząd Patentowy Rzeczypospolitej Polskiej, 09, 2013.

[12] A. Mróz, J. Holnicki-Szulc, and T. Kärnä, "Mitigation of ice loading on off-shore wind turbines: feasibility study of a semiactive solution," Computers \& Structures, vol. 86, no. 3-5, pp. 217-226, 2008.
[13] J. Holnicki-Szulc, C. Graczykowski, G. Mikułowski, A. Mróz, and P. Pawłowski, "Smart technologies for adaptive impact absorption," Solid State Phenomena, vol. 154, pp. 187-194, 2009.

[14] J. Holnicki-Szulc and Z. Marzec, "Adaptive structures with semi-active interfaces," in Proceedings of the EUROMECH 373 Colloquium on Modelling and Control of Adaptive Mechanical Structures, Magdeburg, Germany, 1998.

[15] D. F. Ledezma-Ramírez, N. S. Ferguson, and M. J. Brennan, "Vibration decay using on-off stiffness control," in Proceedings of the International Conference on Noise and Vibration Engineering (ISMA '06), pp. 433-446, Leuven, Belgium, September 2006.

[16] E. F. Gad, T. Nguyen, N. Haritos, and J. Wilson, "Development and application of a new versatile tuned mass damper for floor vibrations," in Proceedings of the 6th World Conference on Structural Control and Monitoring, Barcelona, Spain, July 2014.

[17] L. Gaul and R. Nitsche, "The role of friction in mechanical joints," Applied Mechanics Reviews, vol. 54, no. 2, pp. 93-105, 2001.

[18] A. Mroz, A. Orlowska, and J. Holnicki-Szulc, "Semi-active damping of vibrations. Prestress Accumulation-Release strategy development," Shock and Vibration, vol. 17, no. 2, pp. 123-136, 2010.

[19] Theory Manual, Abaqus FE Software v.6.5, http://manuals.its .virginia.edu/abaqus/Documentation/docs/v6.5/books/stm/default.htm?startat=ch01s01ath01.html.

[20] A. Mroz, J. Holnicki-Szulc, and J. Biczyk, "Semi-active structural node especially for vibration mitigation,” p. 407763, Urząd Patentowy Rzeczypospolitej Polskiej, 042014. 


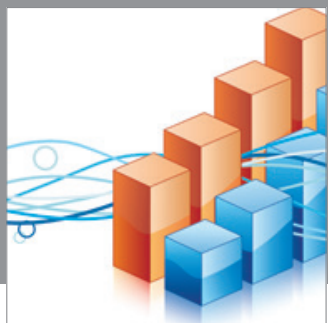

Advances in

Operations Research

mansans

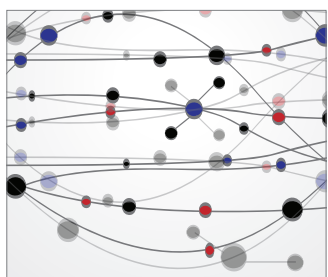

The Scientific World Journal
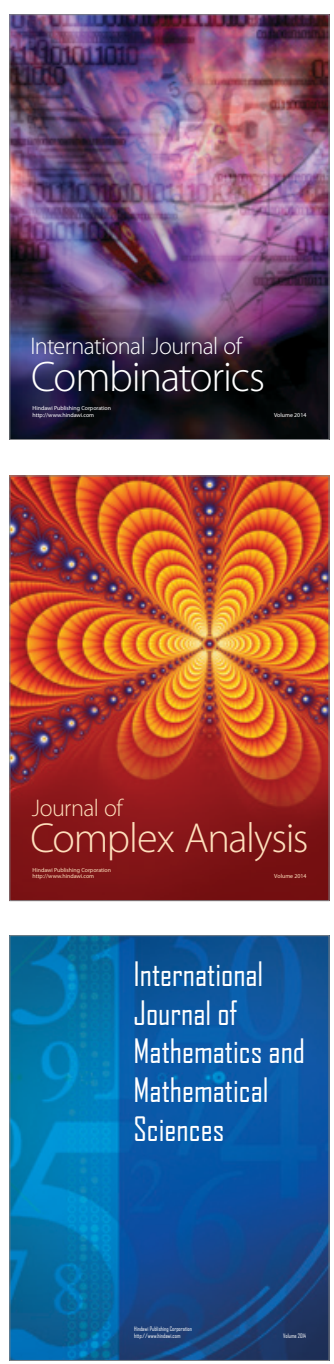
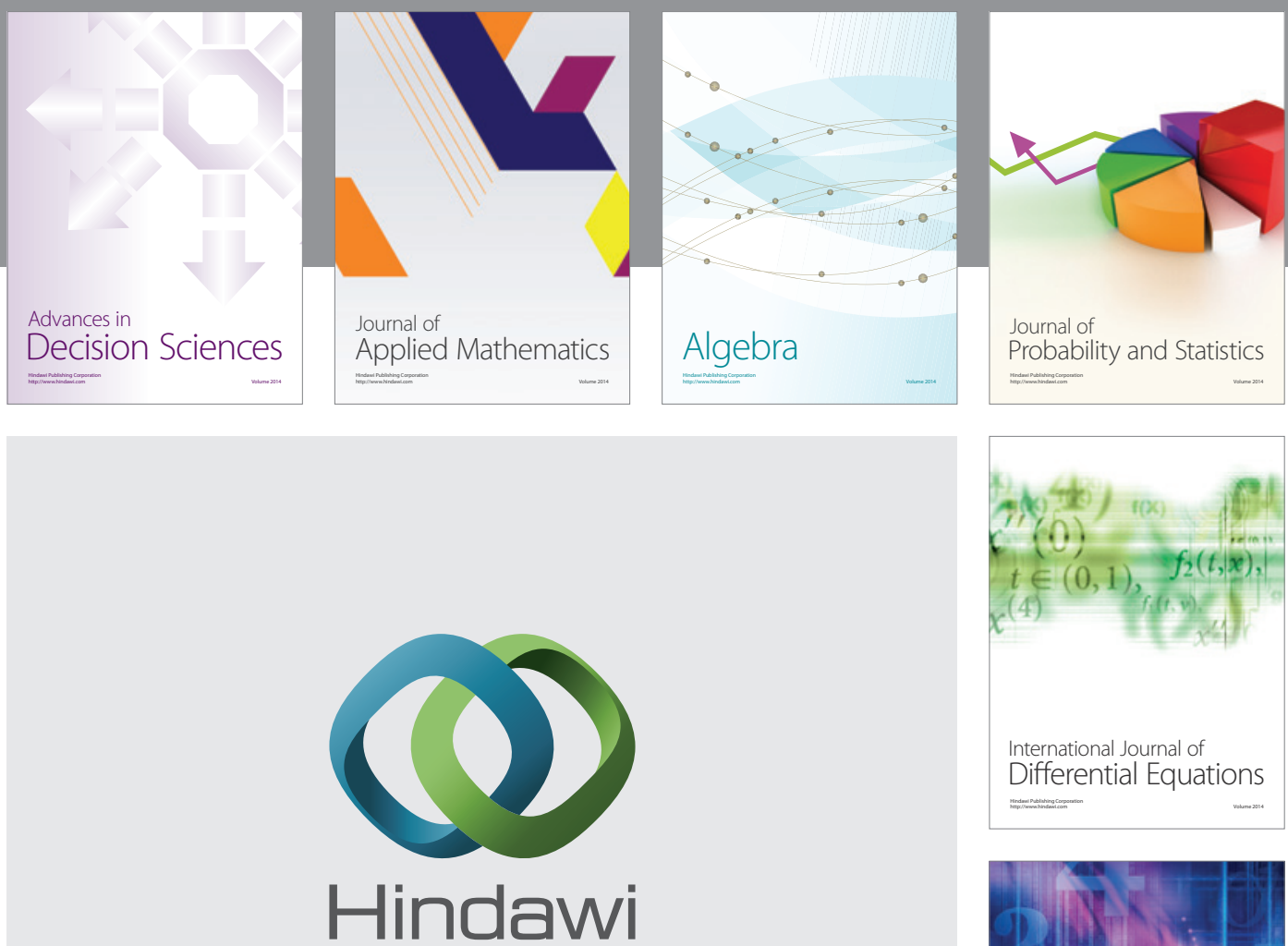

Submit your manuscripts at http://www.hindawi.com
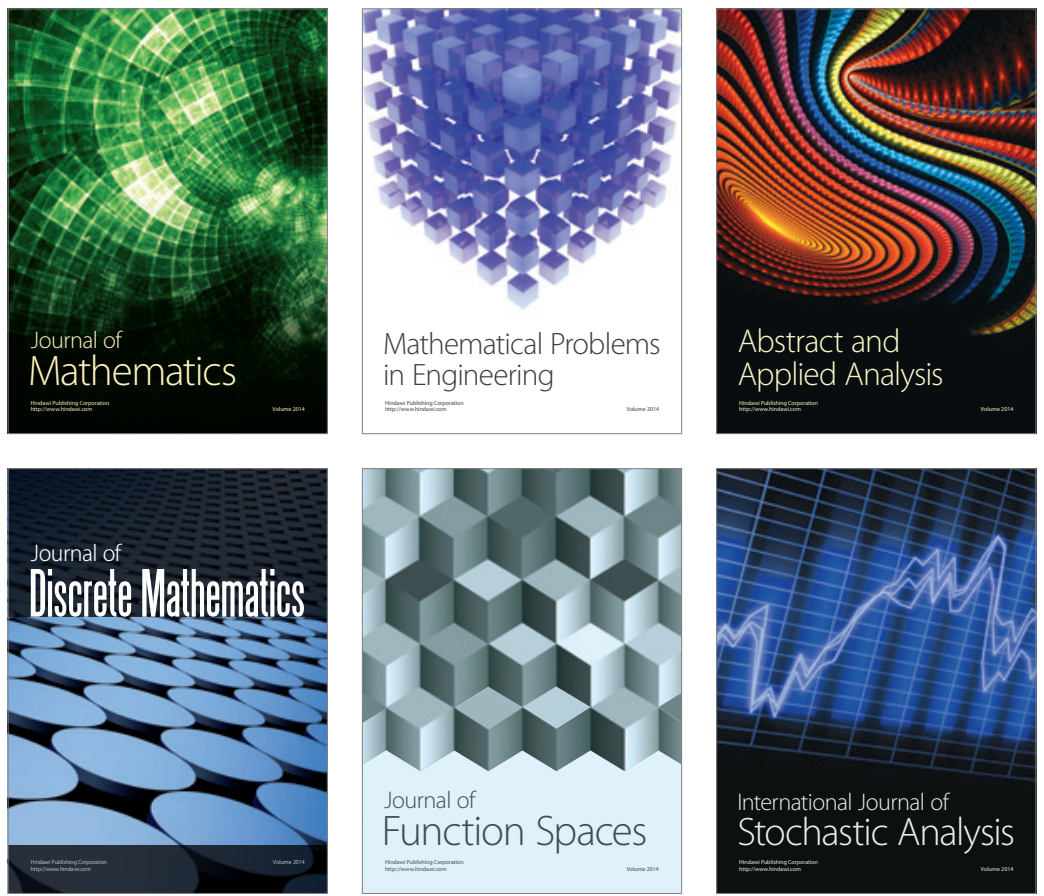

Journal of

Function Spaces

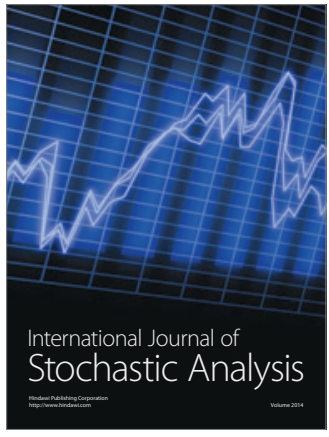

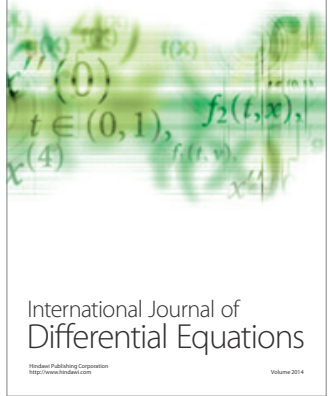
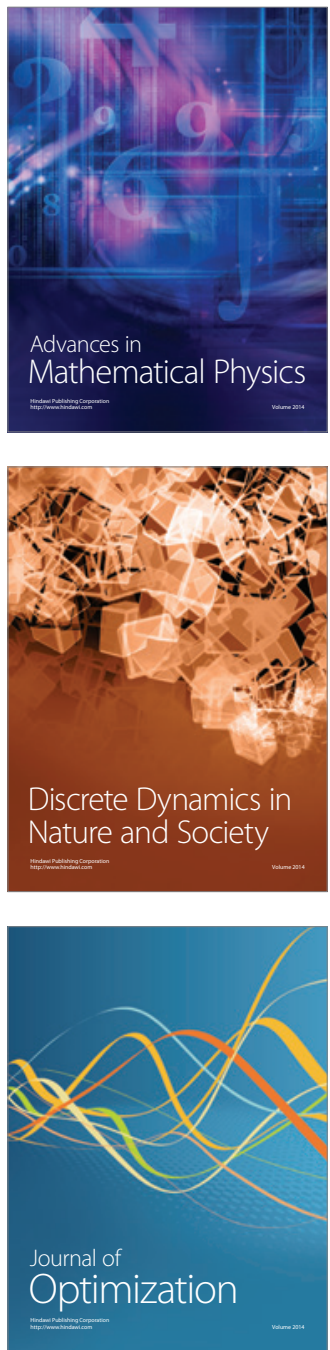